\title{
Defining Problems of Practices to Advance Inclusive Tactile Media Consumption and Production
}

\author{
Abigale Stangl \\ University of Texas \\ Austin, USA \\ stang1@utexas.edu
}

\author{
Ann Cunningham \\ Colorado Center for the \\ Blind \\ Littleton, USA \\ ann@acunningham.com
}

\author{
Lou Ann Blake \\ National Federation of \\ the Blind \\ Baltimore, USA \\ LBlake@nfb.org
}

\author{
Tom Yeh \\ University of Colorado \\ Boulder, USA \\ tom.yeh@colorado.edu
}

\begin{abstract}
Tactile media are important resources for people who are blind or have low vision (BLV) to access visual or graphical information as well as to develop tactile acuity. In this paper we present findings from a social learning design that was guided by the question, "What are the factors or issues that impact the tactile media consumption and production practices of BLV and other invested stakeholders?" From data collected during three Tactile Arts and Graphics Symposia - that gathered ( $\mathrm{N}=64)$ BLV and sighted practitioners, researchers, and educators invested making information and experiences accessible through touch - we identified 34 issues that fall under four problems of practice, that impact tactile media practices. Based on these four problems of practice (and 34 underlying issues), we share recommendations to support the development of sociotechnical systems that improve tactile access to information and full inclusion of people who are BLV in tactile media consumption and production.
\end{abstract}

\section{Author Keywords}

Tactile media; tactile graphics; tactile art; accessible art; problems of practice; visually impaired; social learning; blind; low vision; inclusion; production; consumption; tactile literacy.

\section{ACM Classification Keywords}

Human-centered computing Empirical studies in accessibility • Human-centered computing Interface design prototyping - Social and professional topics $\sim$ People with disabilities - Hardware Tactile and hand-based interfaces.

\footnotetext{
Permission to make digital or hard copies of all or part of this work for personal or classroom use is granted without fee provided that copies are not made or distributed for profit or commercial advantage and that copies bear this notice and the full citation on the first page. Copyrights for components of this work owned by others than ACM must be honored. Abstracting with credit is permitted. To copy otherwise, or republish, to post on servers or to redistribute to lists, requires prior specific permission and/or a fee. Request permissions from Permissions@acm.org.

ASSETS '19, October 28-30, 2019, Pittsburgh, PA, USA

(C) 2019 Association for Computing Machinery.

ACM ISBN 978-1-4503-6676-2/19/10, \$15.00

DOI: https://doi.org/10.1145/3308561.3353778
}

\section{INTRODUCTION}

Over the past forty years, the human-computer interaction (HCI) community has been working to devise technical and socio-technical solutions to address what Buxton (1986) called a "gap between computer accessibility by disabled and nondisabled populations", which "appears to be widening rather than narrowing" [15]. One such area of socio-technical research has focused on the design of access technologies to make visual media and information accessible for people who are blind or have low vision (BLV) through the sense of touch. In fact, over the past twenty years computer scientists and mechanical engineers have focused on the development of technical systems that aid users in the design and production of tactile media. Tactile media are representations of visual information that can be accessed through the sense of touch or medium, that when touched, evoke metarepresentation.

Such scholars have focused on the design and development of technologies that present tactile transmutations of visual media through physical mediators. Bliss et al. (1970), for example, created a system to produce a tactile image through a 24-by-6 array of pins driven by piezoelectric bimorphs [11]. Today scholars and industry leaders continue to refine the design of dynamic pin-based displays that can create refreshable graphics. For example, the American Printing House for the Blind (APH) and Orbit Research have conducted field tests towards the development of Graphiti, a "dynamic multilevel tactile touch display". This display is stated to "allow students and adults to access a wide variety of on-screen graphics [pie charts, bar graphs, geometric forms, maps, floor-plans, flow-charts, line drawings, and dynamic graphical content] by touch."

Amidst the development of such pin-based systems, others have focused on the employment of additive manufacturing processes and materials [14,65,70], electromagnetic coils [69], and robots [28] to create tactile representations of visual and graphical media. Others still have focused on the development of technical systems to support tactile media design process, including the development of specialized graphical user interfaces and [4,41], and employment of computer vision $[33,61,73,74]$. These technical efforts complement a variety of more traditional or analog tactile media production tools $[18,72,77,78]$. 
It is important to note that much of the aforementioned work centers on tactile graphics (maps, charts, graphs, and diagrams). While in recent years scholars have also started to look at the transmutation of artistic media (pictures, illustrations, paintings, multimedia experiences) $[16,40,61]$, such work is more limited. In this paper we address tactile graphics and art production and consumption alike.

It is also important to note that many people who are BLV have not been positioned or prepared-in practice and in research - to participate in the creation of artistic content and content area graphics alike. Those who have started to look at how to increase BLV peoples' inclusion in production have sought to create accessible design practices $[7,8]$, develop non-visual drawing tools [12,26,57,69,70], develop tangible storytelling applications [9], and develop accessible coding systems [39]. While important, many of these efforts have not been deployed beyond the lab; the space of inclusive media consumption and production in practice is largely unexplored.

The work we present in this paper is motivated by this understanding, as well as the aim to invigorate HCI scholars and practitioners to consider a host of factors that influence the living practices of people who are invested in tactile media consumption and production. To do just this, in this paper we present findings from three Tactile Art and Graphics Symposia (TAGS). Sixty-four total participants (49\% of whom are BLV) participated in the TAGS, during which they engaged in hands on activities and discussions about their practices and the state of tactile media consumption, production, and instruction. We collected data during each TAGS with the intent of answering two research questions:

1. What are the factors/issues that impact the art and graphic consumption and production practices of BLV, and sighted people invested in tactile media consumption and production?

2. What do the factors/issues reveal about the problems of practice (POPs) related to tactile media that tactile media practitioners and scholars encounter?

POPs are defined as "persistent, contextualized, and specific issue embedded in the work of a practitioner, the addressing of which has the potential to result in improved understanding, experience, and outcomes" [55]. POPs are generally identified through reflection on practice, dialogue with colleagues, and looking at the quantitative and qualitative research literature on the topic; they are not usually based on individual cases but involve a group of people or a particular population $[17,48]$. Identification of POPs is a common strategy used during co-design [54] and design-based implementation research where teachers and researchers come together to either adapt or create curriculum materials or technology [52].
By employing the POPs lens to the development of technical systems, we highlight that tactile media consumption and production is a complex and interconnected socio-cultural issue. We also provide a series of recommendations that can be used to guide socio-technical systems that support inclusive tactile media consumption and production.

\section{STUDY DESIGN AND METHODS}

\section{Tactile Art and Graphics Symposium Design}

The aforementioned research questions and intent for the TAGS emerged through the formation of a Research Practice Partnerships (RPP) between three of the co-authors. RPPs are collaborations where practitioners and researchers join forces to investigate and address POPs - in formal $[19,53]$ and informal [10] learning environments - through the original analysis of data collected during interventions [19]. The RPP members include:

- An access technology researcher (sighted) at a US-based university who is interested in "broadening inclusion of all people to become media designers";

- A tactile artist and educator (sighted) of BLV individuals who aims to cultivate experiences where "thought leaders coalesce, touch the same objects in situ, and compare their tactile experiences to advance the field";

- A representative of the National Federation of the Blind (NFB) and tactile art advocate (legally blind), who along with her colleagues at the national advocacy organization, considers the appreciation for and enjoyment of art as part of "living the life we want." The NFB sponsored the TAGS.

During the initial TAGS planning meetings, we found a sense of mutualism based on the shared observation that people who are BLV consistently encounter barriers that limit their opportunities to consume and create/produce art and graphics. Furthermore, we noted that there are few forums where a breadth of practitioners and scholars who consume, produce, and instruct with tactile media can come together and discuss the issues that impact their practices, compare experiences, and envision solutions.

These two mutually defined objectives guided the design of the TAGS and iterative evaluation of the procedures we used during each event implementation. In the end, our objective for each TAGS was to create a forum where practitioners and scholars could discuss the issues that impact their practices, compare experiences, and envision solutions. Based on the fact that the participants came with varying degrees of experience consuming and producing tactile media, we designed the TAGS as social learning experiences [3] that drew on constructionist [51] principles. Social learning theorists define learning as active social participation in the practices of a community [42,75] and emphasize the dynamic interaction between people and the environment to the construction of meaning and identity [47]. As such, learning is a process of social change through which people 
learn from each other in ways that can benefit wider socialecological systems [60].

Throughout the design and implementation of the TAGS we drew on the following definitions of the various media formats.

- Tactile Graphics: Representations of data and information presented using raised lines, points, and areal textures that are intended to be felt rather than seen and are a means by which blind people access maps, graphs, diagrams and other graphical representations [1];

- Accessible Art: Art created to be accessible through nonvisual means or artistic content that is made accessible through sound and labels. One primary type of accessible art is Tactile Art.

- Tactile Art: Pictures, illustrations, sculptures, and multimodal compositions that are accessible through the sense of touch. In some cases, tactile art is crafted intentionally for touch-focused experiences. In other cases, the label tactile can be applied to art that produces a tactile or haptic response when touched. Tactile art is differentiated from tactile graphics in that it not created with the intent of representing information.

Of note, while we drew on these definitions throughout the TAGS planning, we were also aware that the distinction between art and graphics is ambiguous; whether something is considered tactile graphic versus tactile art greatly depends on the creator's intent for the work, and the contexts in which the media is being consumed.

We also drew on the following notions of consumption and production to design the events.

- Consumption is at the end of the line of activities that starts with evaluation of available resources and proceeds through production, distribution, and use of media [25].

- Production is any creative activity involved in the manipulation of materials into a consumable good or service (creation, craft, design, and manufacturing). Production practices are agentive, support selfdetermination [64] and literacy [71].

The consumption-focused activities that we designed and implemented at the TAGS centered on providing participants with opportunities to identify and discuss "touch points" or common reference points from which discussion could emerge and techniques to focus their tactile attention on the nuances of interpreting the media. In addition, we hoped that participants could develop a shared vocabulary about tactile experiences, and discuss the state of accessible tools, materials, and the resulting media. For example, during the "Art Fitness" activity, we asked participants to walk around the tactile art exhibit in small groups and explore each piece of art under sleep shades and to reflect on a series of questions: 1) What can you feel (through the sense of touch)? 2) What would it mean if something was different? 3) What was the artist's intent? Using the same questions, in another activity-focused on tactile graphics consumptionparticipants spent 20 minutes at five tables looking at unique sets of tactile graphics.

We also designed a series of tactile media productionfocused activities to support participants to identify and discuss their practices, engage in the critique of production methods used to create the media, learn about methods and technologies, and share successful strategies for developing inclusive creation experiences. For example, to focus participants attention on tactile art production, we invited participants with expertise in non-visual clay sculpting, collage, wire sculpting, lapidary arts, and/or stone carving to introduce the other participants to these medium and artistic practices. Over the course of 1.5 hours participants engaged in three such activities. Similarly, during the TAGS participants had an opportunity to work in small groups to practice creating tactile graphics using Braillers, foam and other paper and wiki sticks to collage graphics, a Sensational Blackboard [77] to create raised line drawings.

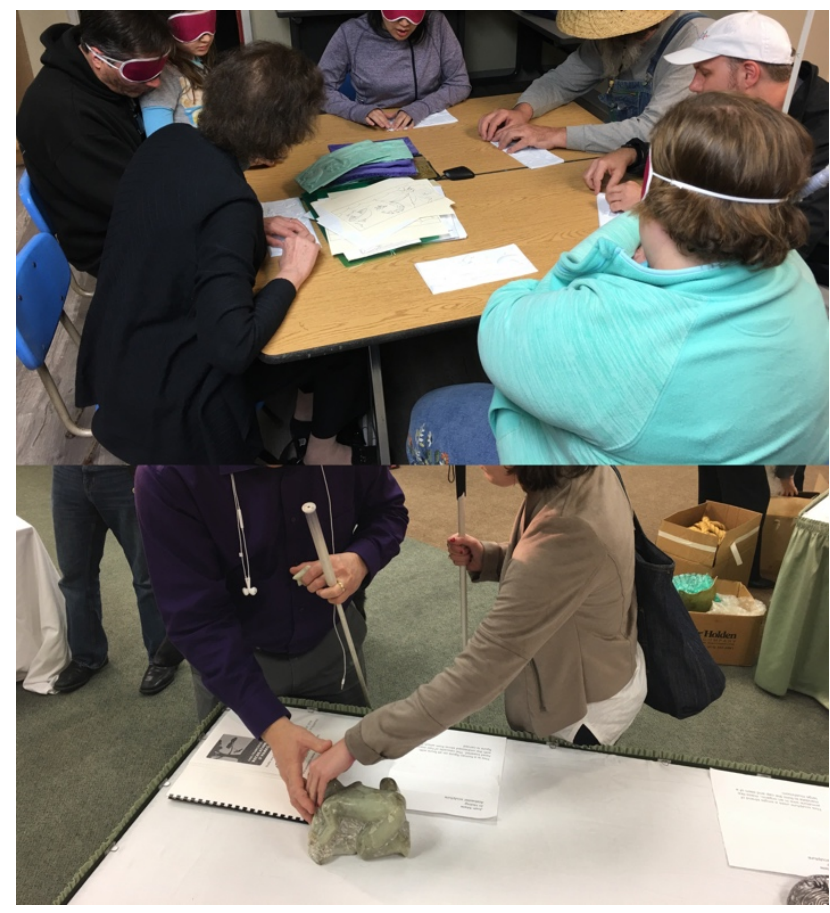

Figure 1. TAGS Tactile Media Consumption Activities.

\section{Participants}

$\mathrm{N}=68$ people participated in our study. Approximately $33 \%$ of the 64 study participants were totally blind, approximately $15 \%$ of the participants have low vision, and approximately $51 \%$ of the participants had no significant visual impairment (Table 1). Importantly, we opted to limit the capacity of each TAGS to 30 attendees based on our aim to create an event where BLV and sighted tactile media practitioners could engage in meaningful conversations and have purposeful interactions within a range of tactile media and tools. Eight participants attended more than one of the TAGS events based on their sustained interest and role of leading activities. 


\begin{tabular}{|c|c|c|c|}
\hline & Blind & Low Vision & Sighted \\
\hline \multicolumn{4}{|l|}{ Tactile Art } \\
\hline Artists & 10 & 6 & 7 \\
\hline Art Educators & 0 & 0 & 3 \\
\hline Museum Curators & 0 & 0 & 4 \\
\hline \multicolumn{4}{|l|}{ Tactile Graphic } \\
\hline Tactile Media Designers & 4 & 0 & 9 \\
\hline Access Technologists & 2 & 1 & 3 \\
\hline Rehabilitation Educators & 3 & 1 & 0 \\
\hline Teachers of the Visually Impaired & 0 & 1 & 6 \\
\hline \multicolumn{4}{|c|}{ Researchers (representing ASSETS interests) } \\
\hline Technology Researchers & 3 & 0 & 3 \\
\hline Social Science Researchers & 1 & 1 & 5 \\
\hline Science Researchers & 1 & 0 & 3 \\
\hline \multicolumn{4}{|l|}{ Other Stakeholders } \\
\hline Blindness Advocates & 4 & 3 & 0 \\
\hline Total & 28 & 13 & 43 \\
\hline$\%$ & 33.33 & 15.48 & 51.19 \\
\hline
\end{tabular}

Table 1. TAGS Participant by Vision Level/Profession Across TAGS

To recruit TAGS attendees (and research participants) we sent invitations to people we know to be engaged in tactile media practices. Soon after the invitations were sent, other practitioners and scholars contacted the NFB for an invitation. In these instances, we sent emails to the initial invitees and then accepted attendees on a first-come, firstserved basis until 30 spots were filled. We invited other interested parties to subsequent TAGS.

\section{Data Collection Procedure}

Prior to each event, we notified the participants that the TAGS would be recorded for research purposes. We obtained consent at the onset of each TAGS; attendance was not contingent on consent to participation in the study. One attendee did not consent to participate in the research; their data were excluded during analysis and not reported.

During each of the TAGS the first author took field notes during the activities and placed three audio recorders and video cameras around the rooms to capture the participants' conversations in the large and small group activities. After redaction of segments that were inaudible (because too many people were talking or they were too far from the microphone), approximately 8 hours of audio data per event were transcribed by a professional transcription service. After all three TAGS we implemented, the first author performed a retrospective, grounded theory analysis to identify emergent themes in the data [68]. This process involved several steps of analysis. Using qualitative data analysis software Dedoose [79], the researcher-RPP member began by performing a round of coding to identify segments of dialogue within the transcripts where participants directly addressed the four general topics guiding the design of the TAGS, referred to here as Structural Codes (art consumption, art production, graphics consumption, graphics production). Second, we performed invivo coding, or the assignment of a word or short phrase to data excerpts, to ensure that concepts stay as close as possible to research participants' own words or use their own terms [22]. The invivo coding enabled us to identify recurring "issues", important topics or problem for debate or discussion that emerged during all three TAGS. We then used the coded to write analytical memos that identify and name the recurring issues that participant's face, which became the four POPs we in the findings section.

\section{FINDINGS}

In this section we present examples from our data that evidence the participants experiences and the factors that impact their practices. In total we identified a total of 34 important issues across the four Structural Codes-art consumption (AC), art production (AP), graphics consumption (GC), graphics production (GP) (Table 2). We present these findings according to four overarching POPs that emerged during analysis: 1) Conspicuousness Impacting Belonging, 2) Stigma of Touch, 3) Inadequate Educational Programming/Supply and Dissemination of Tactile Media; 4) Instability of Tactile Media Design Resources.

\section{POP \#1) Conspicuousness Impacting Belonging}

TAGS participants repeatedly shared that people who are BLV often experience a sense of conspicuousness when engaging in tactile media consumption and production, which reduces their sense of belonging. In regards to art consumption (AC3), a blind access technology specialist noted: "When I go to art exhibitions and want to touch the art, one thing that stands as a barrier for me is when I feel like I am part of the exhibit; when my experience as a blind patron becomes the focus of the other people's attention. It really distracts me from what I am there to experience." Throughout the TAGS, participants attributed their sense of conspicuousness to other people's curiosity, exhibit design decisions that situate them as "other", and museums professionals' lack of preparedness to support blind visitors (AC4). To this later point, a sighted museum curator asked during the third TAGS, "How do we move the idea of access out of just sort of the transactional, service model, and really think about it creatively so museums and arts and cultural organizations don't just think of it as the law, but as a strategy to support all patrons."

In relation to art production (AP3), an artist with low vision attending the third TAGS remarked, "When you go into an art school as a blind person [...] there's a psychological barrier that you feel, like I'm not supposed to be here." Similarly, regarding tactile graphics consumption, several of the BLV TAGS participants discussed the fear of blocking other people's view of visual while taking the time that they needed to read tactile graphics in public settings.

While it is well established that many people who are BLV experience a range of psychosocial experiences related to their visual impairments [45] —including not feeling a sense of belonging or inclusion in museums [20,37] as well as 
other environments $[24,35,50]$, this finding emphasizes the need to consider conspicuousness in the development of socio-technical systems that support tactile media consumption and production. Baumeister and Leary (2017) explain that the need to belong is a fundamental human motivation and takes precedence over self-esteem and selfactualization [5].

\section{POP \#2) Stigma of Touch}

In addition to experiencing conspicuousness during tactile media consumption and production, the BLV TAGS participants described a wide array of experiences when they were prohibited from tactually exploring their environments - $\mathrm{a}$ factor that they attribute to a societal stigma placed on touch. Pallasmaa (2012) explains that in western cultures touch and tactility have historically been passed over in many fields since vision is regarded as the "noblest of the senses" [49]. Jehoel et al. (2006) note that research in perceptual and cognitive psychology is predominantly centered on visual and auditory information processing, not tactile perception and cognition [34]. Regarding stigma more generally, Goffman (1963) described stigma as "an attribute that links a person to an undesirable stereotype, leading other people to reduce the bearer from a whole and usual person to a tainted, discounted one [23]".

To this point, a blind artist shared that when engaging in art creation she has been forced to confront a "culture that prohibits and stigmatizes touch." She explained, "I have spent so much of my life fighting to get to do stuff that other people are telling me, no, no, you cannot do it. Here's a situation where somebody is saying to me you can do it [live model sculpting], and I am feeling resistance, it is like okay, let's get over this because this is really an opportunity (AP2). " Her art teacher, also attending the TAGS, explained that he spent a lot of time fretting over how to tell his school administration that he was allowing a student to touch the nude model; he was concerned that he would be reprimanded and possibly fired.

Many of the TAGS participants indicated that they do use touch to explore their environment, they get the sense that they are deviating from the norm (AC5); that the stigma of touch imposes limitations on when and how they engage in tactile exploration of fine art and other cultural environments. As one TAGS participant noted, "I feel strongly that touch is a very maligned sense. It is the only sense that we have that people constantly tell people not to use it. No one ever says, 'Don't look. Don't listen. My god, don't taste that.' But we commonly, commonly, excessively hear, "Don't touch." Others provided descriptions of their experiences; a blind artist and craftsman recalled, "They [an art museum] had this cool kinetic sculpture outside. When I stuck my hand in it this sweet docent, who comes up to me and says, 'You cannot touch that. You know, you get sand on your face, and it gets on the floor, and people got to clean that up." During the second TAGS, a director of an independence training center said, "Most people are taught not to touch. It is critical that that changes."

While researchers have recognized stigma as an important factor in the design and adoption of assistive technologies $[38,59,66]$, few efforts have been made to explicitly investigate how and when the stigma of touch impacts how people who are BLV engage in tactile media practices, and in turn how to devise socio-technical strategies that reframe touch away from deviance into a universal avenue of engagement.

POP \#3) Inadequate Educational Programming, and Supply and Dissemination of Tactile Media

Throughout the TAGS, many of the BLV participants shared that they desire, yet are rarely exposed to educational opportunities and resources that support tactile consumption and production. The TAGS participants' experiences are reflective of recent studies that found BLV students often do not develop the skills to efficiently and accurately access graphical information due to a lack of direct instruction in using tactile media [6,76]. Hayhoe $(2008,2017)$ describes that the lack of opportunities for people who are BLV to engage in art consumption occurs in society through active and passive forms of exclusion [29,30]. One form of passive exclusion is the lack of diversity of accessible content - an issue TAGS participants identified as well (AC2).

When speaking about tactile graphics, in particular, the participants often specified academic areas where graphics were missing, namely spatial literacy and math instruction (GC2). As one participant shared, "I have seen a lot of art and graphics as a sighted person, but my experience as a blind person has been surprising-there has been a huge absence of accessible art and a huge lack of information."

When describing a project that provided people with tactile maps of their neighborhood, a blind researcher, artist, and engineer recalled, "Many people would be crying[...] when they saw these maps... They would recognize the streets that they knew and become emotional about getting access to this kind of information - that had never been available before. It is something that so many of us have always wanted and needed. And many of us stopped thinking that it was something we could have." Also regarding tactile maps, a tactile graphics producer attending the TAGS reflected, "We spend a lot of time getting feedback on the maps that we make. People often say they are great, that they love them, they say 'they are gorgeous,' but then they ask, 'but then what do we do with them?"

The last quote also exemplifies that people will not gain tactile and spatial literacy without exposure to tactile media. Regarding spatial literacy, a BLV researcher in the field of haptic perception and haptic displays squarely identified that: "Spatial literacy for blind people is becoming really important for the workplace and I think it's something that we have to send people out into the world with skills that they can bring with them to accomplish the jobs they need to." 
As the TAGS participants spoke about tactile and spatial literacy, they often exclaimed the importance of developing tactile literacy skills when BLV students are young through the creation of multimodal materials for co-reading (GC3) and exposure to "a diversity of materials-just as any sighted person would want different representations" (GC6). However, the participants also noted that there is not a universal tactile graphic code to support people in developing techniques and confidence to read tactile graphics that can progress from basic concepts such as shapes to more complicated representations of data found in Science Technology Engineering and Math graphics (GC4). A BLV participant attending the first TAGS noted, "Blind kids can't process complex tactile information. If you create a graphic, it better be really simple. And, you know, that is not the truth...it is about building for that learning curve. Building the scaffolding and education to build up what is a tactile graphic and how do you layer it. Just like a sighted child doesn't start with the final product, they spend years developing their visual literacy."

TAGS participants also described the of the lack of opportunities to touch tactile art (AC9). A blind participant noted, "For anybody who's ever done that [taken advantage of official museum touch tours], you will know that the quality of these opportunities varies wildly. Sometimes it is really rewarding. Sometimes it is essentially a waste of time." Others described instances when the lack of access to materials and tools inhibited their inclusion within creative experiences. For example, a participant reflected on their experience in art class as a child stated, "I was only allowed to use clay. I was never allowed to draw. I always felt left out." An art educator who is BLV reflected, "Probably $60 \%$ of the kids [who are blind] come to my summer course wouldn't have known what the tools on the table were."

An activity during the third TAGS, where a blind artist and her sighted studio art instructor described and demoed how they co-created an inclusive studio art class experience in a live model sculpting class, highlighted the rarity-yet the importance of - experiences where people who are BLV are positioned as producers and leaders in instruction (AP6). During this activity many of the TAGS participants asked questions about how to engage in tactile observation - a core teaching and learning tool in art education that they had never experienced (AP4). For example, one participant asked, "So, would you plan to [touch the object or model] in the beginning so that you were not blocking people's points of view, or disrupting their process? Or would you kind of wait until a break to get the information you need?" Others were interested in how to use touch to gauge proportion, and whether using touch as an observation tool yielded similar results to observing with vision.

Regarding access to tools to support teaching and learning with tactile media, the TAGS participants reflected that many people who are BLV do not have access to many digital design tools for the creation of tactile art (AP8) or tactile graphics (GP3). A sighted computer science researcher reflected, "There is a great need to provide better access both to creative tools but also to creative works." Similarly, an access technology specialist noted, " a lot of creation technologies are so new, we really need to build maybe a collaborative forum to get user feedback about the inaccessibility of these tools." A participant with acquired blindness shared, "I used to love graphic design. Now, I don't even know where to begin. All of the design programs I used are no longer accessible to me." During the first TAG Symposium, a tactile graphic designer who is blind stated, "Any technical platform being used to create and distribute tactile materials should be accessible...especially new technical programs that strive to improve the workflow of making tactile graphics."

In addition to the lack of accessible tactile media teaching and learning tools, several TVIs attending the TAGS shared that they are not trained in how to support their BLV students in creating art and that many mainstream art teachers are not familiar with strategies used to support BLV peoples' learning (AP5). One TVI at the first TAGS noted, "Learning and appreciation of art should come through the public schools; however, my experience as a TVI was that I received no training on how to accommodate students. When I began my career as a TVI, I asked my mentor about what to do, they did not have any idea. They said, 'It is just art, it does not matter.'...This is a common attitude." Another TVI and behavioral therapist from an early intervention center noted, "I spend a lot of my own time trying to come up with new ways to help kids integrate with their surrounds and experiences that are accessible...but I don't feel prepared to create art experiences or adapt art tools and materials."

The tactile designers attending the TAGS similarly reflected that there are no formalized programs that teach tactile graphic design to sighted or BLV designers (GP4). A TVI attending the second TAGS reflected, "I never was taught how to design tactile graphics in school. Everything I have learned, I learned with students, and through comparing strategies with other teachers. " A sighted producer attending TAGS 1 noted, "I have had to learn [to create tactile media] on my own. It is nice that other people have gone through similar things, but how can we make it easier for others?" The TAGS evidence concurs with prior findings that there are no guidelines for TVI or other stakeholders on how to introduce tactile graphics or art to their students or how to teach them the systematic use of tactile media as tools to gather information, nor are there guidelines on preparing tactile media for visually impaired print readers [62]. Trainings for TVIs to learn how to design, use, and teach with assistive technologies are limited [63].

Finally, across all three TAGS, participants expressed a desire for a common lexicon of words to be able to communicate with others about tactile experiences (AC12). For example, a low-vision TAGS participant shared, "I had to find out on my own that there are a lot of different ways to 
touch art. There's a very delicate touching with the fingertips. There's touching that happens with the whole hands, the whole fingers. There's touching that evolves enveloping the object [...] Grasping, pinching, tapping, lifting, circulating, manipulating, grasping with the hands and the upper arms, and so on. " As exemplified by this last quote, when discussing various pieces of tactile art at each TAGS the participants generated vocabulary of different types of tactile experiences. They also shared a desire for more opportunities to discuss the nature of how to define tactile art (AC11). To this later point, after an art consumption experience, one participant shared, "We talked about whether the meaning of abstract art could be conveyed non-visually and whether abstract art can be meaningful to blind people... Tactile forms may be pleasurable to touch, but not inherently help convey the intention of the artist or the meaning of the artwork."

\section{POP \#4) Instability of Tactile Media Design Resources}

As indicated above, the development of educational programming for tactile media design is in part contingent upon the development of resources used to design and teach the design of tactile media. For example, across all TAGS events, participants noted a difficulty in finding and acquiring quality tactile graphics for instruction (GC5). Accordingly, the fourth problem of practice that we identified centers on the nascency and role of design standards in the creation of quality tactile graphics.

The TAGS data revealed that there is still disagreement within the tactile graphic design community about tactile graphic design standards being universally codified (GP4). By codification, the participants referred to whether there should be a universal standard specifying which symbols and patterns to use within all types of tactile graphics. On one hand, some of the participants argued that we are not ready for codification. A blind artist, engineer, and researcher stated, "Let the standards emerge because sometimes standards dampen creativity and give the impression that if you are following the guidelines, then you are doing it right. Not true." When talking about tactile map design standards, another participant cautioned against codification of design standards for maps; "Each element on a map needs to be palpably different from each other, it is difficult not to use symbols that others have used to represent other elements. I am reluctant to call for codification. [...]I am not opposed to standards, but I do advise caution in locking things up when we are still trying to figure things out." A sighted access technology specialist noted, "The guidelines and standards that are available are the standards for tactile graphics, but not necessarily for map making. It is more about where things should be placed, how things should be readable regarding lines and distances between objects, how to use lead lines to indicate if you are labeling something",

When talking about guidelines across each TAGS, participants noted that many tactile graphics are designed to be visually appealing rather than tactilely legible - a practice that needs to be systematically addressed (GC7). These comments concur with previous findings that designing from a visual orientation often results in clutter and detail that is not directly translatable to the sense of touch $[1,31,43,62]$. After an action group activity, several TAGS participant suggested that a set of tactile graphics design considerations that help people think critically about the affordances of vision via touch may be better than a set of established guidelines - a point that is congruent with prior work indicating a need for a "design principle" approach to the design of accessible information systems versus a problembased approach [56].

Regardless of whether or not tactile graphic design should be codified, the TAGS participants noted that there is not a consistent protocol or method for evaluating how different design decisions and corresponding guidelines impact the learnability of graphics (GC9). During the third TAGS, a TVI noted, "I do not think that we are that far from it [a standard set]. I think that is where is going to be the push for standardization because ultimately tactile graphics are used on the SAT or the ACT...I think that if you teach tactile graphics as a subject matter, you want to teach it in a systematic way...in school, you teach kids how to read maps the same as you teach them how to read Braille. There's a system to teach Braille, but to reach that point [with tactile graphicacy] we need consistent materials to start with."

Another TAGS identified factor that affects the fidelity of a tactile graphic centers on whether a tactile graphic producer pairs the design with the appropriate production technology (GC8). As we heard from the TAGS participants, if a design is intended to be produced using a thermoform machine but is printed on swell paper, the tactile experience will be entirely different. This issue was raised by Prescher et al. (2017), who argued for and evaluated tactile pattern set for tactile graphics that can be used across swell, pin-matrix, and embossed production technologies [58]. Other scholars have recently looked at the learnability of concepts based on the application of different production techniques [32,36].

The TAGS participants identified a different suite of design concerns that impact the accessibility of art. Whereas the design considerations for graphics centered on standards, methods of evaluation, effectiveness of production technologies, and how people apply different production technologies to create their designs, the primary issue in art consumption in the POPs focused on the provision of accessible labeling. The TAGS participants noted that there is a general lack of Braille and audio labeling of art (AC7). Additionally, the TAGS participants noted that it is important to provide Braille labels that can be read in an ergonomic position, e.g. horizontal (flat) or at a slight angle. Additional issues included the layout of the exhibit spaces and presentation methods (AC6). While many of these issues have been identified in the museum studies literature $[2,21,27,46]$, they are not ubiquitously addressed in many settings or by the ASSETS community. 


\begin{tabular}{|c|c|c|}
\hline \multicolumn{2}{|c|}{ Art Consumption by BLV } & \multirow{2}{*}{$\begin{array}{c}\text { POP } \\
2\end{array}$} \\
\hline $\mathrm{AC} 1$ & BLV Desire Yet Miss the Opportunity to be Consumers & \\
\hline AC2 & Lack of Consistency and Diversity of Accessible Art & 3 \\
\hline AC3 & BLV Receive Unsolicited Attention as Patrons & 1 \\
\hline $\mathrm{AC} 4$ & Institutions Do Not view Tactile Art as Assets for All. & 1 \\
\hline AC5 & BLV Experience Deviance When Touching Art. & 2 \\
\hline AC6 & $\begin{array}{l}\text { Inaccessible Exhibit Configuration and Layout Inhibit BLV } \\
\text { People from Accessing Art. }\end{array}$ & 4 \\
\hline AC7 & Ineffective Labeling Affects the Accessibility & 4 \\
\hline AC8 & Touch Affects Artistic Materials & 2 \\
\hline AC9 & $\begin{array}{l}\text { BLV are not Exposed to Touch-Based Art Interpretation } \\
\text { Education }\end{array}$ & 3 \\
\hline $\mathrm{AC} 10$ & $\begin{array}{l}\text { BLV and Others Yearn to Discuss Touch-Based Art } \\
\text { Interpretation. }\end{array}$ & 3 \\
\hline $\mathrm{AC} 11$ & No Universal Definition of Accessible and Tactile Art. & 3 \\
\hline $\mathrm{AC} 12$ & No Universal Vocabulary to Describe Tactile Art. & 3 \\
\hline \multicolumn{3}{|c|}{ Art Production } \\
\hline AP1 & Blindness Impacts Opportunity not Desire to Create. & 3 \\
\hline AP2 & Prohibition of Touch Affect If/When BLV Create. & 2 \\
\hline AP3 & Overcoming Being a Spectacle or Not Belonging. & 1 \\
\hline AP4 & BLV Desire, Yet Miss Opportunities to Tactilely Observe. & 3 \\
\hline AP5 & $\begin{array}{l}\text { Lack of Art Education for TVIs/ Lack of TVI Education } \\
\text { for Art Teachers. }\end{array}$ & 3 \\
\hline AP6 & BLV Need Opportunities to Teach Other BLV People. & 3 \\
\hline AP7 & Lack of Access to Accessible Tools \& Materials & 3 \\
\hline AP8 & Many Tools and Materials Are Not Accessible To BLV. & 3 \\
\hline \multicolumn{3}{|c|}{ Tactile Graphics Consumption } \\
\hline $\mathrm{GC} 1$ & Many BLV are Not Exposed to Tactile Graphics. & 3 \\
\hline $\mathrm{GC} 2$ & $\begin{array}{l}\text { Tactile Graphics to Teach Math/ Spatial Literacy are } \\
\text { Limited. }\end{array}$ & 3 \\
\hline GC3 & $\begin{array}{l}\text { Multimodal Reading Materials are Needed to Expand } \\
\text { Meaning-Making for BLV and Sighted Co-Readers. }\end{array}$ & 3 \\
\hline GC4 & A Foundational Tactile Graphicacy Curriculum is Missing. & 3 \\
\hline GC5 & $\begin{array}{l}\text { Finding and Getting Tactile Graphics and Illustrations is } \\
\text { Challenging. }\end{array}$ & 4 \\
\hline GC6 & Unsettled Debate: Consistency vs. Diversity in Media. & 3 \\
\hline GC7 & $\begin{array}{l}\text { Overemphasis on Visual Aesthetics in Tactile Graphic } \\
\text { Design. }\end{array}$ & 4 \\
\hline GC8 & $\begin{array}{l}\text { Designers Often Do Not Pair the Correct Production } \\
\text { Technology/Techniques to Their Design. }\end{array}$ & 4 \\
\hline GC9 & $\begin{array}{l}\text { Need for Methods to Robustly Evaluate Design of } \\
\text { Graphics. }\end{array}$ & 4 \\
\hline GC10 & BLV Learners Need 3D Printed Materials. & 3 \\
\hline \multicolumn{3}{|c|}{ Tactile Graphics Production } \\
\hline GP1 & Cost is Prohibitive in $\mathrm{T}$ c & 3 \\
\hline GP2 & Production Technologies are Often Overrated. & 4 \\
\hline GP3 & Design and Production Technologies are Not Accessible. & 3 \\
\hline GP4 & $\begin{array}{l}\text { Disagreement about Codification of Tactile Graphic } \\
\text { Guidelines Divides Stakeholders. }\end{array}$ & 4 \\
\hline
\end{tabular}

Table 2. Thirty-four issues identified from TAGS concerning tactile art and graphics consumption and production.

\section{DISCUSSION}

Our analysis of the data collected during three TAGS resulted in identification of four POPs (and 34 related issues) that impact practitioners, scholars, and educators invested in tactile media consumption, production, and instruction. At a high level, we see that each of the POPs are interconnected; the successful of socio-technical systems focused on tactile media depends on a holistic understanding of these POPs and the underlying issues. For instance, when developing a tactile media-focused access technology, one should equally consider how the design, distribution, and end-use of such technology will position people who are BLV to touch materials freely (without experiencing the stigma of touch or feeling a sense of conspicuousness), just as one should consider how specific design standards and educational programming can be supported by such technologies.

\section{Recommendations Based on POPs}

Based on the findings presented in this paper, here we provide recommendations to assist the ASSETS community in developing socio-technical systems that enhance inclusion in tactile media consumption and production.

POP \#1: Based on findings related to POP \#1 (Conspicuousness Impacting Belonging), we advocate for the direct involvement of people who are BLV in every stage of design processes, and ubiquity of opportunities where people who are BLV are empowered to choose and mediate for themselves how they are positioned to consume and produce tactile media. For example, we envision a scenario where BLV person leads the development of accessible information systems that enables others to non-visually rank and share information regarding the inclusivity of a mediarich environments and validate the accessibility of specific tactile media in such environments.

POP \#2: Based on findings related to POP \#2 (Stigma of Touch), we advocate for the design of multimodal sociotechnical systems and environments that situate tactile media as a fundamental mode of representation, and as such provide tactile outputs in addition to auditory cues and visual interfaces. This may be achieved, for example, through efforts to organize and employ crowd workers in the transmutation of visual content presented in public environments into $3 \mathrm{D}$ printed objects and raised line drawings (in addition to employing people who are BLV to validate the accessibility of such materials). It may also look like the design pin-based tactile displays as modular components that can be connected to any personal computer and integrated with open educational resources.

POP\# 3: Based on findings related to POP \#3 (Inadequate Educational Programming/Supply and Dissemination of Tactile Media), we advocate for the design and development of socio-technical systems that support one's development of tactile interpretation of artistic, spatial, and data rich media. Key functionalities of such systems may include features that: 1) teach vocabulary that describe haptic or other sensory phenomenon; 2) provide means for non-visual users tangibly 
replicate features that they previously touched; 3) provide different renditions of tactile materials created from visual reference materials; 4) provide access to a diversity of tactile reference materials (paired with sound and braille/large print) that can be used to build one's understanding visual composition; 5) scaffold the delivery of tactile content based on teaching and learning goals and one's prior experience with tactile media; 6) tack available tactile media, and 7) coordinate the dissemination of such materials.

In addition, we advocate for the design and development of socio-technical systems that position people who are BLV to be creators, designers, and producers of their own media. While some scholars have focused on the design of nonvisual drawing tools $[12,26,57,69,70]$, many of such systems have not been deployed at scale "in the wild". We believe that further research on the strategies people who are BLV develop when positioned to create with traditional craft materials and accessible design interfaces, as well as how they adopt such technologies will greatly inform future work.

POP \#4: Regarding POP \#4 (Instability of Tactile Media Design Resources) we advocate for socio-technical research focused on the evaluation of tactile graphic design standards across different types of content areas, production methods, and according to different practitioners' employment of the standards in their design. We advocate for further investigation into the circumstances where established tactile media guidelines [13] satisfy or leave tactile media consumers and producers wanting, as well as the types of resources that support one's ability to engage in metarepresentation and multimodal composition.

\section{Tactile Art vs. Graphics}

Clustering the data according to the POPs also revealed several insights about the differences between the tactile art and tactile graphics. The difference between tactile art and tactile graphics was most apparent under POP \#3, where we saw that people have a stronger notion of what constitutes a tactile graphic then what constitutes tactile art; the participants related to tactile graphics as raised line drawings and 3D models that convey objective information and educational concepts, whereas the task of defining tactile art as more challenging. Some of the unanswered questions posed by TAGS participants include: Should tactile illustrations and pictures be considered graphics or art? If art is tactile, is it only meant for a person who is BLV? If a person who is blind creates art does it have to be characterized as tactile? Can art be used to convey STEM concepts?

POP \#3 also revealed that the participants have slightly different considerations when it comes to instruction of and with different types of tactile media. For example, the issues surrounding educational opportunities centered on tactile art consumption centered on the need for: 1) new interventions to support tactile art interpretation, 2) the development of a common lexicon to describe tactile experiences, and 3) inclusive learning experiences that promote tactile observation and equal access to tools and materials. In contrast, the instructional needs for tactile graphic education centered on: 1) a curriculum and tools to teach tactile graphic design (to all) and 2) a scaffolded tactile literacy-focused curriculum that prepares all BLV students obtain basic tactile literacy competencies that is reflected in standardized tests and the understanding of specific content areas.

The nuance that emerged between tactile art and tactile graphics in POP \#4 highlighted the fact that to make art (tactile and visual) accessible depends on adherence to known strategies for labeling, exhibit set up, program development, and inclusion opportunities for leadership by BLV people in every stage of the exhibit and content curation. In comparison, the TAGS revealed that there is still contention as to how and whether it is appropriate to standardize tactile graphic design, and the need for more research into how different design practices and pairing of designs with production methods impacts users teaching and learning experiences.

Finally, we noted that despite evidence that conspicuousness (POP \#1) and stigma (POP \#2) impact BLV people's consumption and production of tactile art and graphics alike, it appears that these issues occur more often in respect to engaging in art practices. We believe that this emerged because consumption of tactile graphics often occurs on a one-on-one basis, where art practices more often occur in group settings. Furthermore, most tactile graphics are 2.5 dimensions (raised line), and are thus more discreet to experience through touch than tactile art. We advocate that scholars and practitioners involved in designing tactile media-focused access technologies take note of these differences, and design systems that support consumption and production of both art and graphics.

\section{The Nature of Tactile Media}

Finally, the opportunity to design and implement the TAGS provided us with an opportunity to reflect on the nature of tactile media. Through this work we came to see tactile media as a boundary object. Star (2010) notes, "boundary objects are essentially organic infrastructures that have arisen due to [...] 'information needs' and allow different groups to work together [44]'. In this research, tactile media brought 64 BLV and sighted scholars and practitioners together. In addition, the activities that occurred during each of the TAGS highlighted the fact that the creation, design, and production of any single piece of tactile media requires multiple expertise [67], including that of educators, creators, designers, producers, technology developers, policy makers, funders, etc. Accordingly, we advocate that the ASSETS community view tactile media as boundary objects through which people who are BLV can be positioned as consumers and producers, and through which interdisciplinary teams can build the social and technical infrastructure to access to media and information and the accessibility of consumption and production experiences. 


\section{LIMITATIONS AND FUTURE WORK}

Here we note key limitations to this work and opportunity for future work. First, we did not reach saturation within our data set; future studies would benefit from the inclusion of additional stakeholders and assessment of how different practitioners uniquely experience the POPs. While the RPP did reached out to the broader community during recruitment, we do acknowledge that this study represents a subset of the population involved in tactile media consumption and production and that NFB's sponsorship of the TAGS may have influenced people's decision to participate.

Next, analysis of the data revealed that a slight majority of the TAGS discussions centered on tactile art, despite our efforts to implement an equal mix of activities focused on tactile graphics and tactile art and the fact that representation of people involved in practices related to tactile art and tactile graphics was balanced. One possible explanation may be that the TAGS provided a unique opportunity for participants to co-experience tactile art consumption and production. Further work is needed to distinguish the boundaries between tactile art and tactile graphics and consumption/production.

Finally, in this paper we provide a general set of recommendations to inform the design of inclusive tactile media technologies. In future work, we hope to elaborate on how such recommendations can be deployed during technology design processes. Towards this goal, we will draw on the POP framework provided in this paper to complete a literature review of existing tactile media technologies. Within this literature review we will also take note of how scholars position tactile media - as resources that provided access to versus how they discuss the accessibility of such media. Where access is generally defined as the use of services relative to the actual need for care; lack of access occurs when there is a need for services but those services are not utilized, accessibility of tactile media refers to the degree to which content conveyed within the representation is conveyed through the sense of touch and understood by the consumer, i.e. factors pertaining to the characteristics of a piece of media or media experience. We believe that this distinction may help us better address the barriers to access as well as develop strategies to ensure accessibility of tactile media.

\section{CONCLUSION}

In this work we identify four POPs from set of 34 issues, which impact peoples' tactile media consumption and production: 1) Conspicuousness Impacting Belonging, 2) Stigma of Touch, 3) Inadequate Educational Programming/Supply and Dissemination of Tactile Media; 4) Instability of Tactile Media Design Resources. To identify these POPs we designed and implemented three Tactile Art and Graphics Symposium, where 64 invested tactile media scholars and practitioners gathered to consume, produce, and discuss the state of tactile media. Based on data collected during these events, we identified themes that were recurrent in each of the structural codes+issues areas. We employ the POPs to construct a summary of the issues that impact practitioners' and scholars' experiences with tactile media. Through identifying such issues and POPs, we provide the ASSETS community with a set of recommendations that can be used to advance how technologies are designed to support inclusive tactile media consumption and production.

\section{ACKNOWLEDGEMENTS}

We want to thank those who supported this research. Importantly, we want to support the NFB for hosting and sponsoring the TAGS. We want to thank Colorado Arts in Society for providing a grant to support the curation of the tactile art exhibits hosted at each TAGS. Finally, the research presented in this paper was conducted with the support of an NSF Award \#1615247 and the University of Colorado Chancellor's Award for Excellence in STEM Education.

\section{REFERENCES}

[1] Frances Aldrich. 2008. Talk to the Hand: An Agenda for Further Research on Tactile Graphics. In Diagrammatic Representation and Inference, 344346.

[2] Vassilios Argyropoulos, Magda Nikolaraizi, Thomai Tsiakali, Polychronis Kountrias, Sofia-Marina Koutsogiorgou, and Aineias Martos. 2014. Collaborative Action Research Approach Promoting Professional Development for Teachers of Students with Visual Impairment in Assistive Technology. Journal of International Special Needs Education 17, 1: 33-43.

[3] A. Bandura. 1977. Social Learning Theory. Prentice Hall, Englewood Cliffs, New Jersey, USA.

[4] Mario Batusic and Franz Urban. 2002. Preparing Tactile Graphics for Traditional Braille Printers with BrlGraphEditor. In Computers Helping People with Special Needs, 535-536.

[5] Roy F. Baumeister and Mark R. Leary. 2017. The Need to Belong: Desire for Interpersonal Attachments as a Fundamental Human Motivation. In Interpersonal Development (1st ed.), Rita Zukauskiene, Brett Laursen and Rita Žukauskienè (eds.). Routledge, 57-89.

[6] Carole R. Beal and L. Penny Rosenblum. 2018. Evaluation of the Effectiveness of a Tablet Computer Application (App) in Helping Students with Visual Impairments Solve Mathematics Problems. Journal of visual impairment \& blindness 112, 1: 5-19.

[7] Cynthia L. Bennett. 2018. A Toolkit for Facilitating Accessible Design with Blind People. SIGACCESS Access. Comput., 120: 16-19.

[8] Cynthia L. Bennett, Kristen Shinohara, Brianna Blaser, Andrew Davidson, and Kat M. Steele. 2016. Using a Design Workshop To Explore Accessible Ideation. 303-304.

[9] Peter Bennett, Heidi Hinder, Seana Kozar, Christopher Bowdler, Elaine Massung, Tim Cole, Helen Manchester, and Kirsten Cater. 2015. 
TopoTiles: Storytelling in Care Homes with Topographic Tangibles. In Proceedings of the 33rd Annual ACM Conference Extended Abstracts on Human Factors in Computing Systems (CHI EA '15), 911-916.

[10] Browyn Bevan. 2015. Research + Practice Partnerships in Informal Settings. Research+Practice Collaboratory. Retrieved from http://www.exploratorium.edu/sites/default/files/pdfs/ connectedcollection_partnerships.pdf

[11] J. C. Bliss, M. H. Katcher, C. H. Rogers, and R. P. Shepard. 1970. Optical-to-Tactile Image Conversion for the Blind. IEEE Transactions on Man-Machine Systems 11, 1: 58-65.

[12] Jens Bornschein and Gerhard Weber. 2017. Digital Drawing Tools for Blind Users: A State-of-the-Art and Requirement Analysis. In Proceedings of the 10th International Conference on PErvasive Technologies Related to Assistive Environments (PETRA '17), 2128.

[13] Braille Authority of North America. 2010. Guidelines and Standards for Tactile Graphics. Retrieved November 30, 2017 from http://www.brailleauthority.org/tg/

[14] Craig Brown and Amy Hurst. 2012. VizTouch: Automatically Generated Tactile Visualizations of Coordinate Spaces. In Proceedings of the Sixth International Conference on Tangible, Embedded and Embodied Interaction (TEI '12), 131-138.

[15] W. Buxton, R. Foulds, M. Rosen, L. Scadden, and F. Shein. 1986. Human Interface Design and the Handicapped User. SIGCHI Bull. 17, 4: 291-297.

[16] Luis Cavazos Quero, Jorge Iranzo Bartolomé, Seonggu Lee, En Han, Sunhee Kim, and Jundong Cho. 2018. An Interactive Multimodal Guide to Improve Art Accessibility for Blind People. In Proceedings of the 20th International ACM SIGACCESS Conference on Computers and Accessibility, 346-348.

[17] City, Elizabeth A, Richard F. Elmore, Sarah E. Fiarman, and Lee Teitel. 2009. Instructional Rounds in Education: A Network Approach to Improving Teaching and Learning. Harvard Education Press. 8 Story Street First Floor, Cambridge, MA 02138. Tel: 888-437-1437; Tel: 617-495-3432; Fax: 978-3481233; e-mail: hepg@harvard.edu; Web site: http://www.hepg.org/hep.

[18] Javier Villar Cloquell. 2014. Writing, Braille and Drawings Board for Blind or Visually Impaired Persons. US Patent. Retrieved July 12, 2018 from https://patentimages.storage.googleapis.com/3d/5f/7b/ b1f304b62c7aec/US20140287382A1.pdf

[19] Cynthia E. Coburn, William R. Penuel, and Kimberly E. Geil. 2013. Research-Practice Partnerships: A Strategy for Leveraging Research for Educational Improvement in School Districts. William T. Grant Foundation. Retrieved February 21, 2017 from
https://eric.ed.gov/?id=ED568396

[20] A. Fielder. 2000. Sight unseen.

[21] Silvia Soler Gallego and Antonio Javier Chica Núñez. 2014. Museums for all: evaluation of an audio descriptive guide for visually impaired visitors at the science museum. Revista Española de Discapacidad (REDIS) 2, 2: 145-167.

[22] Lisa M. Given. 2008. InVivoCoding. In The $S A G E$ Encyclopedia of Qualitative Research Methods.

[23] I. Goffman and Erving Goffman. 1963. Stigma; Notes on the Management of Spoiled Identity. Prentice-Hall.

[24] Deborah Gold, Alexander Shaw, and Karen Wolffe. 2010. The Social Lives of Canadian Youths with Visual Impairments. Journal of visual impairment \& blindness 104, 7.

[25] Neva Goodwin, Julie A. Nelson, Frank Ackerman, and Thomas Weisskopf. 2008. Consumption and the consumer society. Global Development and Environment Institute: 1-26.

[26] William Grussenmeyer and Eelke Folmer. 2016. AudioDraw: user preferences in non-visual diagram drawing for touchscreens. In Proceedings of the 13th Web for All Conference (W4A '16), 22.

[27] Beaux Fen Guarini. 2015. Beyond Braille on Toilet Doors: Museum Curators and Audiences with Vision Impairment. M/C Journal 18, 4. Retrieved August 30, 2016 from http://www.journal.mediaculture.org.au/index.php/mcjournal/article/view/1002

[28] Darren Guinness, Daniel Szafir, and Shaun K. Kane. 2017. GUI Robots: Using off-the-shelf robots as tangible input and output devices for unmodified GUI applications. In Proceedings of the 2017 Conference on Designing Interactive Systems (DIS'17). ACM, New York, NY, USA, 767-778.

[29] Simon Hayhoe. 2008. Arts, culture and blindness: studies of blind students in the visual arts. Cambria Press, Youngstown, USA.

[30] Simon Hayhoe. 2017. Blind Visitor Experiences at Art Museums. Rowman \& Littlefield.

[31] M. A. Heller, J. A. Calcaterra, L. L. Burson, and L. A. Tyler. 1996. Tactual picture identification by blind and sighted people: effects of providing categorical information. Perception \& psychophysics 58, 2: 310323.

[32] Leona Holloway, Kim Marriott, and Matthew Butler. 2018. Accessible Maps for the Blind: Comparing 3D Printed Models with Tactile Graphics. In Proceedings of the 2018 CHI Conference on Human Factors in Computing Systems (CHI '18), 198:1-198:13.

[33] Chandrika Jayant, Matt Renzelmann, Dana Wen, Satria Krisnandi, Richard Ladner, and Dan Comden. 2007. Automated tactile graphics translation: in the field. In Proceedings of the 9th international ACM SIGACCESS conference on Computers and accessibility, 75-82.

[34] Sandra Jehoel, Don McCallum, Jonathan Rowell, and Simon Ungar. 2006. An empirical approach on the 
design of tactile maps and diagrams: The cognitive tactualization approach. The British journal of visual impairment 24, 2: 67-75.

[35] Glenda Jessup, Anita C. Bundy, Alex Broom, and Nicola Hancock. 2017. The Social Experiences of High School Students with Visual Impairments. Journal of visual impairment \& blindness 111, 1: 519.

[36] Amy Kalia, Rose Hopkins, David Jin, Lindsay Yazzolino, Svena Verma, Lotfi Merabet, Flip Phillips, and Pawan Sinha. 2014. Perception of tactile graphics: embossings versus cutouts. Multisensory research 27, 2: 111-125.

[37] Georgina Kleege. 2018. More than Meets the Eye: What Blindness Brings to Art. Oxford University Press, New York.

[38] Marion Koelle, Susanne Boll, Thomas Olsson, Julie Williamson, Halley Profita, Shaun Kane, and Robb Mitchell. 2018. (Un)Acceptable!?!: Re-thinking the Social Acceptability of Emerging Technologies. In Extended Abstracts of the 2018 CHI Conference on Human Factors in Computing Systems (CHI EA '18), W03:1-W03:8.

[39] Varsha Koushik and Shaun K. Kane. 2017. Tangibles + Programming + Audio Stories $=$ Fun. In Proceedings of the 19th International ACM SIGACCESS Conference on Computers and Accessibility, 341-342.

[40] K. Kyle, K. Salmon, D. Thornton, and N. Joshi. 2017. Eyes-Free Art: Exploring Proxemic Audio Interfaces For Blind and Low Vision Art Engagement. Proceedings of the ACM. Retrieved from https://dl.acm.org/citation.cfm?id=3130958

[41] Richard E. Ladner, Melody Y. Ivory, Rajesh Rao, Sheryl Burgstahler, Dan Comden, Sangyun Hahn, Matthew Renzelmann, Satria Krisnandi, Mahalakshmi Ramasamy, Beverly Slabosky, Andrew Martin, Amelia Lacenski, Stuart Olsen, and Dmitri Groce. 2005. Automating Tactile Graphics Translation. In Proceedings of the 7th International ACM SIGACCESS Conference on Computers and Accessibility (Assets '05), 150-157.

[42] Jean Lave, Etienne Wenger, and Etienne Wenger. 1991. Situated learning: Legitimate peripheral participation. Cambridge university press Cambridge.

[43] S. J. Lederman, R. L. Klatzky, C. Chataway, and C. D. Summers. 1990. Visual mediation and the haptic recognition of two-dimensional pictures of common objects. Perception \& psychophysics 47, 1: 54-64.

[44] Susan Leigh Star. 2010. This is not a boundary object: Reflections on the origin of a concept. Science, technology \& human values 35, 5: 601-617.

[45] Gunnel Lindo and Lena Nordholm. 1999. Adaptation strategies, well-being, and activities of daily living among people with low vision. Journal of visual impairment \& blindness 93, 07. Retrieved from http://www.afb.org/jvib/jvib930709.asp
[46] Sharon Manship and Eleni Hatzidimitriadou. 2015. Evaluation of the Totally Touchable arts intervention project for sight impaired adults. Canterbury Christ Church University.

[47] M. Muro and P. Jeffrey. 2008. A critical review of the theory and application of social learning in participatory natural resource management processes. Journal of Environmental Planning and Management 51, 3: 325-344.

[48] Karen F. Osterman and Robert B. Kottkamp. 2004. Reflective Practice for Educators: Professional Development to Improve Student Learning. Corwin Press.

[49] Juhani Pallasmaa. 2012. The Eyes of the Skin: Architecture and the Senses. John Wiley \& Sons.

[50] Doxa Papakonstantinou and Konstantinos Papadopoulos. 2010. Forms of Social Support in the Workplace for Individuals with Visual Impairments. Journal of visual impairment \& blindness 104, 3: 183-187.

[51] S. Papert. 1986. Constructionism: A new opportunity for elementary science education.

[52] William R. Penuel, Cynthia E. Coburn, and Daniel J. Gallagher. 2013. Negotiating Problems of Practice in Research-Practice Design Partnerships. Yearbook of the National Society for the Study of Education 112, 2: 237-255.

[53] William R. Penuel, Barry J. Fishman, Britte Haugan Cheng, and Nora Sabelli. 2011. Organizing Research and Development at the Intersection of Learning, Implementation, and Design.

[54] William R. Penuel, Jeremy Roschelle, and Nicole Shechtman. 2007. Designing Formative Assessment Software with Teachers: An Analysis of the CoDesign Process. Research and Practice in Technology Enhanced Learning 02, 51-74. https://doi.org/10.1142/s1793206807000300

[55] Jill Alexa Perry. 2016. The EdD and the Scholarly Practitioner. IAP.

[56] Christopher Power, André Freire, Helen Petrie, and David Swallow. 2012. Guidelines Are Only Half of the Story: Accessibility Problems Encountered by Blind Users on the Web. In Proceedings of the SIGCHI Conference on Human Factors in Computing Systems (CHI '12), 433-442.

[57] Denise Prescher, Jens Bornschein, and Gerhard Weber. 2014. Production of Accessible Tactile Graphics. In Computers Helping People with Special Needs, 26-33.

[58] Denise Prescher, Jens Bornschein, and Gerhard Weber. 2017. Consistency of a Tactile Pattern Set. ACM transactions on accessible computing 10, 2: 7:1-7:29.

[59] Halley P. Profita, Abigale Stangl, Laura Matuszewska, Sigrunn Sky, Raja Kushalnagar, and Shaun K. Kane. 2018. "Wear It Loud": How and Why Hearing Aid and Cochlear Implant Users Customize 
Their Devices. ACM transactions on accessible computing 11, 3: 13:1-13:32.

[60] Mark S. Reed, Anna C. Evely, Georgina Cundill, Ioan Fazey, Jayne Glass, Adele Laing, Jens Newig, Brad Parrish, Christina Prell, Chris Raymond, and Lindsay C. Stringer. 2010. What is Social Learning? Ecology and Society 15, 4. Retrieved from http://www.jstor.org/stable/26268235

[61] Andreas Reichinger, Stefan Maierhofer, and Werner Purgathofer. 2011. High-quality tactile paintings. Journal on Computing and Cultural Heritage (JOCCH) 4, 2: 5.

[62] L. Penny Rosenblum, Li Cheng, and Carole R. Beal. 2018. Teachers of Students with Visual Impairments Share Experiences and Advice for Supporting Students in Understanding Graphics. Journal of visual impairment \& blindness 112, 5: 475-487.

[63] Mohammad Y. Safhi, Li Zhou, Derrick W. Smith, and Pat Kelley. 2009. Assistive Technology in TeacherTraining Programs: A National and International Perspective. Journal of visual impairment \& blindness 103, 9: 562-568.

[64] Kennon M. Sheldon. 1995. Creativity and SelfDetermination in Personality. Creativity research journal 8, 1: 25-36.

[65] Lei Shi, Yuhang Zhao, and Shiri Azenkot. 2017. Designing Interactions for 3D Printed Models with Blind People. In Proceedings of the 19th International ACM SIGACCESS Conference on Computers and Accessibility (ASSETS '17), 200-209.

[66] Kristen Shinohara and Jacob O. Wobbrock. 2011. In the Shadow of Misperception: Assistive Technology Use and Social Interactions. In Proceedings of the SIGCHI Conference on Human Factors in Computing Systems (CHI '11), 705-714.

[67] Abigale Stangl, Chia-Lo Hsu, and Tom Yeh. 2015. Transcribing Across the Senses: Community Efforts to Create 3D Printable Accessible Tactile Pictures for Young Children with Visual Impairments. In Proceedings of the 17th International ACM SIGACCESS Conference on Computers \& Accessibility (ASSETS '15), 127-137.

[68] Anselm Strauss and Juliet Corbin. 1994. Grounded theory methodology. Handbook of qualitative research 17: 273-285.

[69] Ryo Suzuki, Abigale Stangl, Mark D. Gross, and Tom Yeh. 2017. FluxMarker: Enhancing Tactile Graphics with Dynamic Tactile Markers. In Proceedings of the 19th International ACM SIGACCESS Conference on Computers and Accessibility, 190-199.

[70] Saiganesh Swaminathan, Thijs Roumen, Robert Kovacs, David Stangl, Stefanie Mueller, and Patrick Baudisch. 2016. Linespace: A Sensemaking Platform for the Blind. In Proceedings of the 2016 CHI Conference on Human Factors in Computing Systems, 2175-2185.

[71] Vilhelmina Vaičiūnienė and Viktorija Mažeikienė.
2017. Media Literacy and Information Literacy:

Conceptual Convergence into a Conceptual Convergence into a Composite Notion of MIL. Societal Studies 8, 1: 78-94.

[72] Dustin Walsh. Drawing Tools for the Blind. E.A.S.Y. Tactile Graphics. Retrieved January 25, 2018 from http://www.easytactilegraphics.com/

[73] T. P. Way and K. E. Barner. 1997. Automatic visual to tactile translation. I. Human factors, access methods and image manipulation. IEEE transactions on rehabilitation engineering: a publication of the IEEE Engineering in Medicine and Biology Society 5, 1: 81-94.

[74] T. P. Way and K. E. Barner. 1997. Automatic visual to tactile translation. II. Evaluation of the TACTile image creation system. IEEE transactions on rehabilitation engineering: a publication of the IEEE Engineering in Medicine and Biology Society 5, 1: 95-105.

[75] Etienne Wenger-Trayner and Beverly WengerTrayner. 2014. Learning in a landscape of practice: A framework. In Learning in landscapes of practice. Routledge, 27-44.

[76] Kim T. Zebehazy and Adam P. Wilton. 2014. Quality, importance, and instruction: The perspectives of teachers of students with visual impairments on graphics use by students. Journal of visual impairment \& blindness 1, 108: 5-16.

[77] Sensational Blackboard. Sensational Books. Retrieved May 1, 2017 from http://www.sensationalbooks.com/products.html\#blac kboard

[78] Draftsman Tactile Drawing Board. American Printing House for the Blind. Retrieved April 7, 2019 from http://shop.aph.org/webapp/wcs/stores/servlet/Product _DRAFTSMAN\%20Tactile\%20Drawing\%20Board 1-08857-00P_10001_11051

[79] Dedoose. Retrieved July 22, 2018 from https://www.dedoose.com/ 